\title{
Thinking on Three-dimensional Constitution in Teaching Methods of Design Major in the Basic Course of Art and Design
}

\author{
Jingjing Du \\ Suqian College \\ Suqian, China
}

\begin{abstract}
Three-dimensional constitution is the professional foundation curriculum in three-dimensional design. Learning well the curriculum of three-dimensional constitution can cultivate good modeling ability, sensory ability, imagination ability and constructing ability and it is the compulsory course for modern designers. In the process of teaching threedimensional constitution in design major, it is especially of great significance in these aspects, such as the cultivation of imagination, the understanding of form, the grasping of space concept and the training of innovation ability.
\end{abstract}

Keywords-three-dimensional constitution; design major; teaching method

\section{INTRODUCTION}

The purpose of teaching and training of three-dimensional constitution is to lay a foundation for three-dimensional modeling design and improves the modern design ability. The three-dimensional constitution is the professional foundation curriculum in design major, which is based on the possibility of exploring three-dimensional modeling, combining inspiration with meticulous logical thinking. Through the methods of logical reasoning, and combining aesthetics, technology, materials and other factors, three-dimensional constitution determines the final program and lays the foundation for the professional course of design majors.

\section{THREE-DIMENSIONAL CONSTITUTION AND DESIGN}

Design is an activity that includes three-dimensional constitution and considers many other factors to make it become a complete model. The fields of design are very broad, which can be divided into commercial design, industrial design, environmental art design and other categories. These art categories also can be subdivided into advertising design, book design, packaging design, exhibition design, fashion design, textile design, indoor and outdoor environment design, animation design and other professional categories.

The research content of three-dimensional constitution is to extract the three-dimensional factors which exist in various art categories and are correlative from the whole design field, and especially studies their visual effects and modeling features, so as to master scientifically, systematically and comprehensively the basic discipline of three-dimensional form.
Three-dimensional constitution is the professional foundation curriculum in three-dimensional design, which has great distinctions with the specific art categories. There is no limitation of conditions for specific purpose in the whole process of three-dimensional constitution training, so each practice should study the possibility and variability of the form from the perspective of three-dimensional modeling.

Three-dimensional constitution can provide a broad development foundation for design. First of all, learning well the curriculum of three-dimensional constitution can cultivate good modeling ability, sensory ability, imagination ability and constructing ability, and talents with good professional quality of constitution can make excellent designs; Secondly, threedimensional constitution is a kind of comprehensive training including technique and material. In the process of threedimensional constitution, we should combine with the technique and material to consider the feasibility of modeling. Therefore, as a designer, he should not only master the rules of three-dimensional modeling, but also learn and master the knowledge and skills of technique and material and so on, and learning this knowledge is also the compulsory course for contemporary designers; Finally, in the basic training stage, constitution work is a kind of purely formal beauty creation, though without considering its function, the created work can become the rich material for future design. In a word, threedimensional constitution is the compulsory course for excellent designers.

\section{ThE TEACHING METHOD OF THREE-DiMENSIONAL CONSTITUTION}

Three-dimensional constitution is a discipline that studies the three-dimensional form and explores the constitution law, space and application of material among the various elements of three-dimensional forms. Through the study of threedimensional constitution, it can improve the sense of sensibility and appreciation accomplishment related to forms. Studying three-dimensional constitution, firstly, we must comprehend the concept and characteristics of three-dimensional constitution, and then understand the nature of threedimensional constitution by understanding and grasping these features. 
To study three-dimensional constitution, it needs the firm faith and pioneering spirit. Based on the characteristics of three-dimensional modeling, we should constantly train the ability of spatial transformation and three-dimensional imagination, and cultivate the ability of generalization, abstraction, and association of the forms, which requires that learners should have a good and acute sense of modeling and appropriate methods of expression.

\section{A. The Cultivation of Imagination}

Imagination is one of the basic abilities which must be trained in learning three-dimensional constitution. One who does not have good imagination will not achieve the transition from the form in the plane to the state in three-dimension. The imagination of three-dimensional form is the basic ability to finish the creation of three-dimensional constitution, which needs the repeated learning and training to the basic modeling, so as to improve students' transfer ability and threedimensional imagination from the plane to three-dimensional space. "Fig. 1" is a three-dimensional modeling which takes lifestyle as the prototype and encourages students to image and create works.

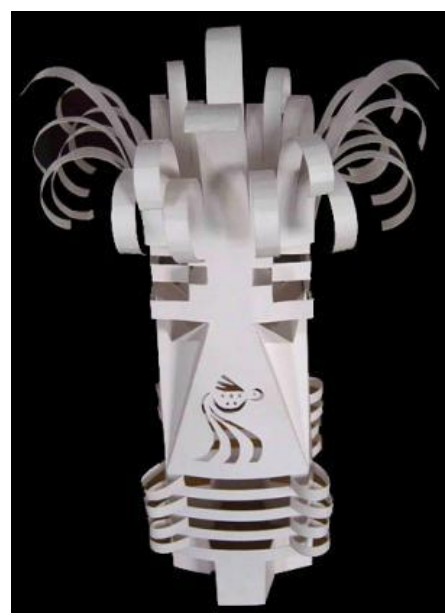

Fig. 1. Modeling Imagination.

\section{B. An Understanding of Three-Dimensional Form}

Form refers to the way of expression of internal essence of things under a certain condition, including the two aspects of form and modality. The meaning of this concept lies in unifying the internal and external things. Form can be divided into conceptual form and realistic form. Conceptual form only exists in the mind of people. Realistic form refers to the appearance which can be seen and touched, including concrete form and abstract form. Concrete form refers to the specific image of nature, including natural form and artificial form. Natural form refers to the existing objective forms in nature which are not transferred by human will, such as flowers, grass, trees, rocks, clouds, flowing water and so on. Artificial form refers to the human-made forms, such as houses, buildings, industrial products, clothing and so on. Any human tangible culture comes from the natural enlightenment and is affected by nature. Abstract form refers to the transformation from conceptual content to perceptual image, and this kind of image is different from the objective image of the reality and is a kind of conceptual symbol. "Fig. 2" deepens the understanding and application of form elements through the combination of training on point, line, plane, and block.

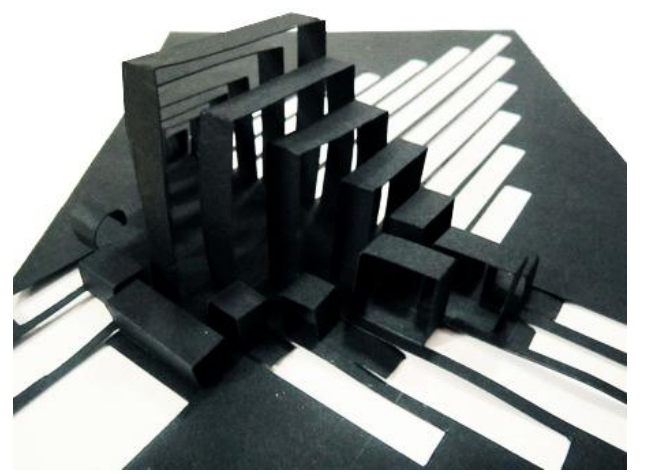

Fig. 2. Expression of Form Element.

The research of three-dimensional constitution is realistic form, which consists of form elements, such as point, line, plane, and block and other combinations. From the perspective of essence of composition, three-dimensional constitution applies the idea of decomposition and combination to observe, understand and create form, which is the scientific innovative thinking of modeling activity.

\section{Grasp the Spatial Concept of Three-Dimensional Constitution}

Space is composed of three dimensions of substancelength, width and height. Space can be roughly divided into physical space and mental space. Physical space is the limited space by entity, but mental space is the space which does not exist but can be experienced, that is, the sense of space. Mental space is the space that people can perceive when they are stimulated by spatial information and conditions, and its nature is the expansion of entity to the surroundings. It is the direct effect environment produced by human perception, which not only includes natural environment, but also includes so-called cultural environment. The cultural environment is the created "world" based on specific people, specific era of world outlook, world view and social outlook, so the creation of space is diverse and polyphyletic. In other words, space should satisfy the material needs and spiritual needs of human beings, and must further have the stability of their own existence of forms. Gestalt psychology has already verified that the visual image is not always the mechanical copy of perceptual material, but a kind of creative grasp towards reality, and what it has grasped images are the image of beauty with rich imagination, originality and sense of sensitivity. In this case, as the designers, they should try their best to give the viewers more imaginary space to exert and additionally hint, inspire and guide. Physical space is easy to understand, but psychological space has more artistic effect. "Fig. 3" is the self-selected architecture or self-created architecture. Using materials to establish models can build up a clear spatial thinking and lay a foundation for the design of three-dimensional modeling. 


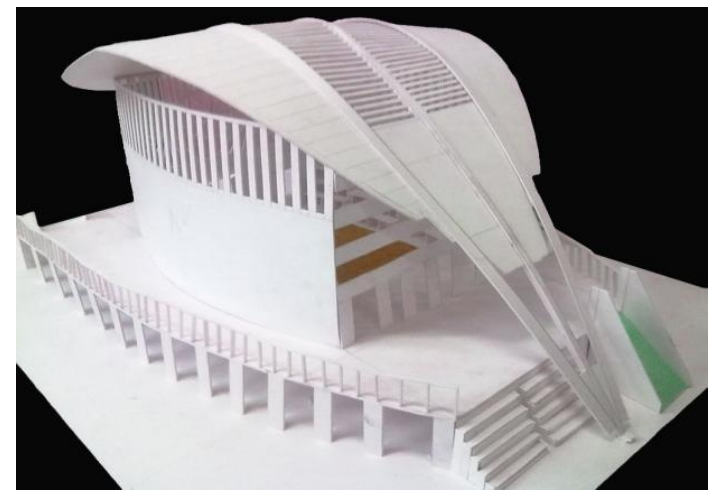

Fig. 3. Spatial Simulation Training.

\section{Material and Structure Training of Three-Dimensional Constitution}

The form we touch in our daily life is made up of different materials. The different compositions of objects need to choose the adaptive materials according to their application. For example, bricks are used to build houses to make them have the solid characteristics; glass is used to constitute windows to make them have the characteristics of transparency and lighting; materials are used to make clothes to let them soft and close to the skin. Using different materials to constitute the similar objects will bring people with different psychological feelings. For example, the fabric sofa will make people feel kind and soft; the wooden sofa will give people a sense of primitive simplicity and stillness; the leather sofa can make people feel luxurious and splendid. Therefore, the selection and combination of materials have a vital effect on the effectiveness of three-dimensional constitution. "Fig. 4" is the material constitution training. Students can choose the existing materials to do the constitution according to the demands of forms, which can cultivate students to positively find around materials and reasonably express themselves combining with the texture of materials.

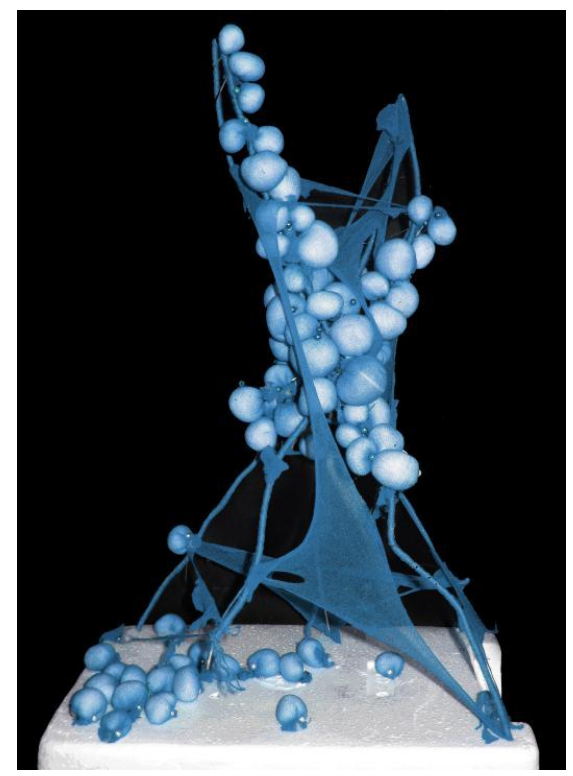

Fig. 4. Material Constitution Training.
In the three-dimensional constitution, the feeling of material quality is a kind of comprehensive experience of touch and vision, therefore, the key point of the use of materials is not the utilization materials of the original "form", but the surface condition of the subjects that make people generate the sense of beauty by touch and vision. That is to say, the understanding of the sense of material quality and the vital modeling of construction of the material are the key points for the material application in the three-dimensional constitution. To realize this goal, except the research of the characteristics of the material itself, we also need to study the processing means of materials and performance techniques of different materials so that the material can play a better effect in three-dimensional constitution.

Of course, different materials and different combinations can bring to different three-dimensional modeling. By deepening the understanding of the materials, using materials reasonably, studying the internal connections and rules of structural forms, and processing the coordination and unification between forms and other trainings, and the practical modeling manipulative ability can be improved.

\section{E. Stimulating Inspiration}

Inspiration refers to a kind of unique mental state and thinking activity which is hidden in creator's individual consciousness, and it is also a kind of creative ability. The appearance of inspiration is really not without basis, and inspiration appears in the process of thinking of the subject, and only in the advancing process of thinking can the inspiration suddenly appear in certain accidental situations. Although inspiration sometimes appears by accident, the contingency is a kind of subconsciousness which is formed by the creative subject for a long time to think, explore and practice. No one can realize what time inspiration will occur, but consciousness provides the appearing possibility of inspiration. Any kinds of inspiration are the epiphany of the creative subject in thinking and exploration. The stronger the desire degree of the expression of mentality and intention is, the closer to the realm of inspiration it approaches.

Therefore, to gain inspiration, the creators should pay attention to and strengthen the practice of their internal strength to rise abruptly based on their accumulated strength. Instead of waiting for the advent of inspiration, we should store enough energy and opportunities for inspiration.

\section{F. Developing Abstract Ability of Forms}

Most students cannot grasp the space well, and the essential spatial form is intuitive and easy to comprehend, but it is difficult to understand the imaginary space of the internal forms. Therefore, first of all, we should cultivate the student's three-dimensional sense and make them grasp the volume of material objects. We can select some simpler forms of object to analyze and understand the internal structure, and then we can simplify the form and modeling to the geometry block with the simplest way, for instance, forms such as cubes, cones, spheres, rectangles and so on are applied to shape practice. In the threedimensional constitution, the training of abstract form is very significant. We must grasp the characteristics of natural forms and gain a kind of basic idea to create a new form and 
modeling according to some laws and rules. "Fig. 5" is an abstract expression of a specified form, which can cultivate students to grasp the thematic characteristic elements from the concrete body and train their ability of abstract expression.

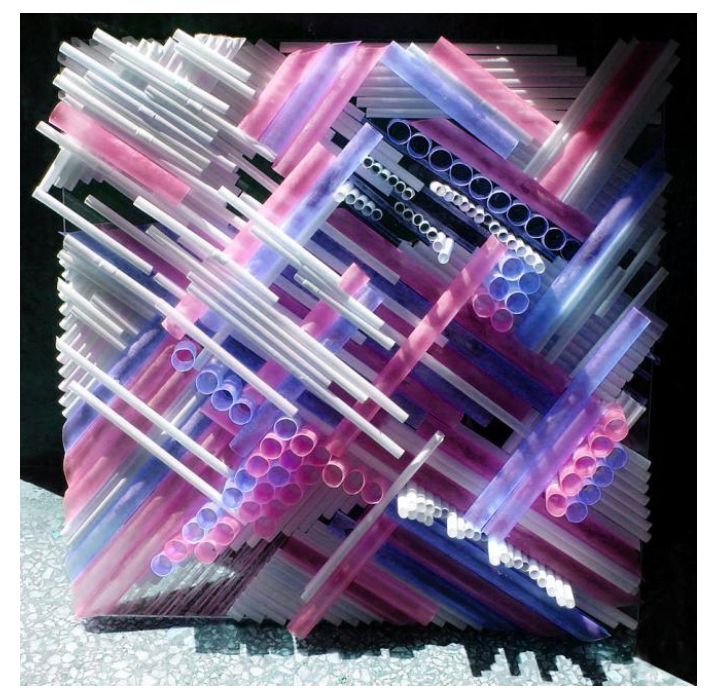

Fig. 5. Abstract Expression of Form.

\section{G. Cultivating Innovative Thinking Ability}

The study of three-dimensional constitution can not only stay listening and practicing in the classroom, but also keep observing and comprehending in practice. Besides finish these traditional exercises, we should also bring the project design and creative thinking design into the study, and think dependently and innovate actively. We can also improve the aesthetic level and the cognitive ability of design by visiting home furnishing market and museum and other ways. From the realistic structures, we can observe, comprehend and analyze the conceiving methods and design concepts of designers, and can experience the openness and unlimitedness of creativity and broaden the vision of imagination.

\section{CONCLUSION}

In a word, the teaching of three-dimensional constitution is a kind of comprehensive training, which specifically brings form elements of various modeling into studying and training field. By training students with various themes and forms can give them a real experience in the construction, attributes, processing methods, the order of beauty, visual language and other aspects of materials. Moreover, we should guide them to study, analyze and abstract the form elements of various modeling such as function, form and texture and others, so as to improve their performance ability, creativity, exploration ability, experience ability and good design feelings.

\section{REFERENCES}

[1] Qin Min. Teaching Reflection on the Course of Three-Dimensional Constitution[J]. Youth Literator, 2012, (26):119-121.

[2] Qiao Hongjuan. Three-Dimensional Form to Explore Course Teaching Reform[J]. Design, 2013, (6):148-149.
[3] Zhou Hongbing. Current Situation and Outlet of Aesthetics Teaching in Colleges and Universities[J]. Beauty \& Times, 2014(8).

[4] Li Yan. Course Design Strategy Analysis of Three Dimension Construction in American University[J]. Art and Design(Theory), 2017, (1):150-152. 